\title{
Formas de contar: "Os gafanhotos" e A costa dos murmúrios
}

\section{Raquel Trentin Oliveira*}

\begin{abstract}
Resumo: O presente artigo analisa um uso do conto para o romance. A Costa dos Murmúrios (1988) de Lídia Jorge divide-se em duas narrativas, uma de abertura, intitulada "Os gafanhotos", que pode ser considerada, pela sua estrutura, um conto, e o romance propriamente dito, dividido em nove capítulos que não recebem títulos. Com essa forma, a narrativa "contrasta duas ficções à procura da verdade" (JORGE, 1993) alimentadas por acontecimentos vividos durante a Guerra Colonial, entre Portugueses e Moçambicanos. Nossa atenção recai sobre o primeiro relato, notando a forma que permite considerá-lo como um conto, além de verificar a organização da sua história e do seu discurso, em que se observa o uso da ironia e da metáfora, contribuindo para o efeito inquietante da narrativa.
\end{abstract}

Palavras-chave: "Os gafanhotos"; estrutura do conto; metáfora; ironia.

\begin{abstract}
This essay analyzes a specific and an interesting use of the short story to the novel. Lídia Jorge's A Costa dos Murmúrios (1988) presents two narratives. The first narrative, entitled "Os gafanhotos", can be considered to be a short story according to its structure. The second narrative is the novel proper, which is divided into nine chapters with no headings. With such a structure, the narrative "contrasts two fictions in search of the truth" (JORGE, 1993), which are fostered by the events occurred during the Colonial War between the Portuguese and the Mozambicans. Our attention concerns the first report. We intend to check the form that allows us to consider it to be a short story. This paper also aims to examine the organization of this fiction's plot and speech, in which the use of ironies and metaphors contribute to the disturbing effect of the narrative.
\end{abstract}

Keywords: "Os gafanhotos"; short stories structure; metaphor; irony.

\section{Introdução}

O romance A Costa dos murmúrios (1988), de Lídia Jorge, surpreende, já à primeira vista, por apresentar duas narrativas - uma de abertura, intitulada "Os gafanhotos", e uma outra, distribuída em nove capítulos não titulados -, cada qual com um narrador específico. Em extensão, a primeira corresponde, aproximadamente, a um capítulo da segunda. As duas narrativas diferem no modo de narrar e na história que contam. No entanto, a segunda alude à primeira a todo tempo, como se quisesse desmascarar a maneira como os acontecimentos foram ali representados.

\footnotetext{
* Raquel Trentin Oliveira é doutoranda do Programa de Pós-Graduação da Universidade Federal de Santa MariaRS, orientada pela Profa. Dr. Sílvia Carneiro Lobato Paraense.
} 
A narradora da segunda narrativa, em primeira pessoa, toma a palavra para refutar esse outro relato que abre o romance - possivelmente de um jornalista africano -, narrado em terceira pessoa, que aparecera sobre a sua vida e de outras personagens portuguesas participantes da guerra em Moçambique. É sobre essa narrativa, mais curta, com forma de conto, que a nossa atenção recai aqui.

Eikhenbaum (1976, p. 163) lembra que o conto "consiste em colocar uma equação a uma incógnita, é um enigma", enquanto o romance "é um problema de regras diversas que se resolve através de um sistema de equações". Assim parece funcionar o diálogo entre as narrativas de $A$ costa dos murmúrios. No romance propriamente dito, a narradora-protagonista "revela e alarga o que antes se apresentara como enigma".

Para falar sobre tal assunto, consideram-se aqui os aspectos que, na bibliografia sobre o conto, são indicados repetidamente como os mais característicos dessa forma da prosa, uma vez que se tem consciência de que o conto pode ser "el más definible y el menos definible de los gêneros" (PACHECO, 1993, p. 13). A extensão do relato, a economia, a condensação se solidarizam para alcançar a unidade e a intensidade do efeito, que é potencializada também por procedimentos de estilo e de elaboração da linguagem (idem). A argumentação do presente artigo gira em torno desse último aspecto, verificando principalmente como um discurso irônico e mais metafórico contribui para a intensidade do efeito.

\section{A história de "Os gafanhotos": "Um momento cheio de encanto"}

A primeira parte de A costa dos murmúrios, "Os gafanhotos", narra a comemoração do casamento do alferes português Luís Alex e sua noiva portuguesa Evita, durante dois dias, em que ocorre uma trégua nos combates contra os levantes coloniais. A comemoração das bodas se dá no terraço do hotel Stella Maris, onde um cortejo de convidados dança inebriado, num clima de "gáudio e furor", enquanto um fotógrafo registra as cenas de harmonia da festa. Do cortejo, além dos noivos, destacam-se Forza Leal, o capitão que traz uma cicatriz à mostra, e sua esposa, Helena, de inigualável beleza, também chamada Helena de Tróia. Dançam, comem, divertem-se em demasia.

Entretanto, o clima eufórico das personagens é ameaçado por pequenos fatos como a aglomeração de cadáveres de negros na praia. Os membros do cortejo nupcial apenas observam, através de binóculos, a imagem destes "imensos, incontáveis afogados", que eram varridos da vista da cidade em caminhões de lixo. Diante do acontecimento, as personagens

\footnotetext{
${ }^{1}$ Comentário na contracapa de A costa dos murmúrios. Lisboa: Dom Quixote, 1988.
} 
insistem em se manterem tranqüilas, observando tudo de longe, achando desculpas que diminuíssem seu valor trágico e guardando uma visão que as favorecesse.

Logo as luzes do terraço são veladas por uma chuva verde de gafanhotos. A chegada de um jornalista africano é tomada como ameaçadora e Luís Alex se propõe a expulsar o intruso, para restabelecer a "calmaria" e a "paz" do ambiente. O cortejo, do terraço, observa a perseguição do alferes ao repórter até que "ambos desapareceram e ouviu-se um ruído parecido com um fósforo de metal que deflagra, fez-se silêncio no terraço e a atmosfera cheirou a pólvora" (ACM, p. 37). A surpresa é que a vítima não é o jornalista e sim o noivo que aparentemente se suicida. A Evita resta apenas abeirar-se do corpo, "lavar-lhe o buraco da testa por onde a bala havia entrado pelo próprio punho do alferes, e beijá-lo na boca até ser manhã" (ACM, p. 38).

\section{3 “Os gafanhotos": uma estrutura de conto}

"Os gafanhotos" pode ser percebido como um tipo de texto particular dentro da narrativa maior de A costa dos murmúrios, sobretudo por possuir título, epígrafe e "FIM" próprios. Pode ser definido como conto, de modo mais visível e imediato, por sua relativa brevidade (30 páginas). Além disso, como se observa a partir da história narrada, representa uma ação de tempo curto que se passa em um espaço limitado, rejeitando digressões e extrapolações. Com essa forma, mantém uma organização una e concisa dos seus elementos. Segundo SARAIVA (1992, p.68), que analisa a questão da dualidade que enforma A costa dos murmúrios, "Os gafanhotos" contém as características de um conto moderno: ritmo veloz, condensações e elipses, poeticidade, dramaticidade, enigmatismo, final precipitado.

No conto, principalmente por suas dimensões reduzidas, são poucas as personagens que atuam realmente. Assim acontece em "Os gafanhotos". Salientam-se Luís e Evita, até por serem o motivo da festa, e o Capitão Forza Leal e Helena, pela singular aparência - os únicos que recebem nomes e um mínimo de descrição. Os outros são "o major de dentes amarelos", o "Comandante da Região Aérea", "a mulher do capitão piloto-aviador". São "fardas extremamente parecidas" que povoam o terraço.

As ações concentram-se em dois dias, na cidade da Beira, mais especificamente no Stella Maris, e podem ser ordenadas em poucas seqüências: a boda (de Evita com o alferes Luís), as cenas eventualmente chocantes no Stella Maris; os negros envenenados; a praga de gafanhotos, a morte do noivo. Tais cenas vinculam-se para responder a um único objetivo, 
produzir um único efeito: o esmorecimento da euforia, do equilíbrio e da harmonia, ainda que as personagens lutem para mantê-los intactos. Acontecimentos inesperados se somam abruptamente, deixando no leitor a impressão de uma catástrofe, mas a surpresa é que as personagens não a percebem.

A tensão é permanente, não havendo relaxamentos intermediários, pois há uma condensação dos principais eventos, sem enxertos de descrições, comentários ou juízos. O foco narrativo mantém a objetividade, atendo-se a observar os acontecimentos de fora e de cima. Predominantemente, o diálogo é direto e a perspectiva, das personagens, mesmo quando a voz é do narrador. O acontecimento vale por si, suprimindo-se explicações morais e didáticas. Esse tipo de foco favorece o desenvolvimento enigmático do conto: do terraço não é possível ver o que realmente aconteceu com o noivo; da mesma maneira, o motivo do envenenamento dos negros não é verificado ou explicado, apenas são ouvidas supostas causas enunciadas pelos oficiais, como morte por afogamento ou pela ingestão de metanol confundido com vinho.

É a narradora da segunda parte de A costa dos murmúrios que se detém em esmiuçar/ recriar os fatos. Ela sugere que os negros haviam sido envenenados e que o soldado Luís morreu em um jogo de roleta russa, que ele próprio - seguindo os conselhos do capitão Forza Leal - armara a fim de acabar com o jornalista que, na verdade, era o amante de sua noiva. Essa intriga passional foi, isto sim, um modo de apagar uma das importantes testemunhas dos subterfúgios usados pelos chefes militares portugueses na guerrilha contra os negros.

Por seu lado, a estrutura econômica e rigorosa do conto se não esclarece em minúcias os acontecimentos, concorre para uma força de impacto, capaz de deixar o leitor suficientemente chocado e interessado por eles, que terminam em suspenso e misteriosos. Assim, esse uso particular do conto n' A costa dos murmúrios tem a função de criar uma imagem surpreendente e enigmática, que estimula a leitura da obra como um todo.

\section{A ironia e a metáfora: recursos potencializadores da surpresa}

Para o efeito inquietante do relato de abertura, contribui uma linguagem irônica e metafórica. Sabe-se que tanto na ironia quanto na metáfora, existe uma seqüência significante e dois níveis semânticos (KERBRAT-ORECCHIONI, 1980, p. 110) - um denotativo (literal) e um conotativo (figurado), mesmo que esses sejam relativos, pois dependem de pressupostos contextuais. No entanto, a ironia se diferencia da metáfora porque ela engendra uma contradição - um "conteúdo patente positivo" e um "conteúdo latente negativo" (idem, p. 
121) -, idéias ao mesmo tempo oponentes e afins, pondo em tensão a mensagem literal e a mensagem "intencionada". A ironia consiste em dizer o contrário do que se diz, permanecendo, então, um desacordo entre o que se enuncia e o que é compreendido. Para isso, o enunciador propositalmente usa índices lingüísticos que sinalizam, de alguma maneira, a mensagem, para que o enunciatário reconheça e entenda a "não sinceridade" do que está sendo, literalmente, expresso. A "conivência" entre esses dois sujeitos do discurso é necessária para que o alvo da ironia seja alcançado, isto é, para que um terceiro sujeito seja atingido, uma vez que a agressão é uma propriedade fundamental da ironia.

Desse modo, o uso da ironia no discurso literário, ao articular contradições, amplia os significados associados a uma determinada cadeia significante. Tal figura é uma forma indireta de argumentação do narrador, que estabelece uma cumplicidade com o leitor, no sentido de ambigüizar o discurso e abrir possibilidades para uma nova leitura em torno do que está sendo dito. Assim pode, a partir de um vocabulário específico, apontar o ridículo de um comportamento sem fazer menção direta ao problema, desvalorizar uma realidade por meio de termos valorizantes.

Por sua vez, a metáfora consiste em uma comparação abreviada ou subtendida, que parte do estabelecimento de uma semelhança, terminando em produzir uma diferença (COSTA LIMA, 1995), e serve para colocar em interação e em interpenetração ${ }^{2}$ diferentes contextos semânticos. Guarda a dupla visão, a representação sensorial, reveladora do imperceptível, e a projeção animista (WELLEK; WARREN, s.d., p. 244).

A metáfora poética (VIANU, 1967, p. 54-55) possui uma identidade ampla, total, entre os objetos da comparação. É uma estrutura semântica ilimitada, composta de dois planos, um expresso e manifesto, outro latente e profundo, como no sonho. Assim, a interpretação de uma metáfora não conclui em nenhum momento, não se pode esgotar, pois sua profundidade é difusa e ilimitada. Logo, da mesma maneira que a ironia, o seu uso pelo discurso literário favorece a instabilidade semântica e, assim, contribui para a problematização do que é representado. No entanto, tal processo só é ativado com a participação do leitor no estabelecimento dos sentidos subentendidos.

No caso de "Os gafanhotos", a leitura revela que o distanciamento inicial do relator é gradativamente alterado por emissões que sugerem sua opinião sobre aquilo que conta. $\mathrm{O}$ uso abusivo de advérbios de modo sinaliza o discurso irônico:

\footnotetext{
${ }^{2}$ Termos destacados por Todorov e Ducrot em Dicionário das ciências da linguagem (1982), Wellek e Warren em Teoria da Literatura (s.d.) e Costa Lima em A aguarrás do tempo (1989) como característicos da crítica
} 
Mas naturalmente que Helena de Tróia tinha de concitar o olhar. Naturalmente que o capitão reparou nos olhares que choviam como dardos. Naturalmente o capitão esbofeteou a mulher. Ainda mais naturalmente - porque tinha a ver com a dinâmica e a cinética - a mulher ficou encostada ao ferro [...]. Com a face esbofeteada, era naturalmente cada vez mais linda (ACM, p. 29$)^{3}$.

O termo "naturalmente", tantas vezes repetido, aponta para o ridículo da situação, em que, estranhamente, uma mulher é espancada em público, sem reagir e também sem que os demais participantes da cena intervenham, tornando-se ainda mais bela com isso. A incongruência entre essas ações é evidente, sendo ressaltada pelo advérbio e pela expressão, também irônica, "porque tinha a ver com a dinâmica e a cinética". A intercalação de tal excerto à situação narrada provoca o estranhamento do leitor. Assim, denuncia-se o absurdo da violência e da naturalidade exagerada com que as personagens a aceitam. Em outras situações é utilizado o mesmo recurso, o que pode ser observado, por exemplo, em "Infelizmente, muito infelizmente, as guerras eram necessárias para equilibrar o excesso de energia que transbordava da alma" (ACM, p. 38). "Infelizmente", bem como "naturalmente" sugerem que as personagens encaram os acontecimentos como fatalidades, como se a violência e a guerra fossem inevitáveis.

Em outro trecho, pode-se observar, pelo exagero, a apatia das personagens diante do que acontece com os negros: "o cortejo estava ainda todo dançando e comendo $e$ bebendo, quando se começou a ouvir correrias pela avenida e gritos do lado do Chiveve, o braço do mar. Mas por isso não valia a pena suspender absolutamente nada do que se estava a fazer $e$ que era dançar e rir intensamente" (ACM, p.16). O emprego repetido do "e" dimensiona a intensidade da festa que é posta em paralelo com o barulho da praia, resultante do pavor causado pela imagem dos corpos trazidos pela maré. A adversativa "mas" rompe a tensão e, somada à expressão "absolutamente nada", denuncia o exagero da indiferença daqueles que festejam em excesso, como reforça o final do fragmento, incapazes de atentar para a tragédia. Tais formas e usos agridem a imagem do cortejo e denunciam sua posição diante do sofrimento que ocorre nesse mesmo tempo.

Dessa maneira, a ironia do narrador se estende sobre todo o relato, dando sinais da incompatibilidade da história, do ridículo das ações, do excesso de naturalidade com que as personagens encaram os fatos, por mais absurdos e intoleráveis. Uma festa de casamento em meio às ações do conflito colonial já apresenta sinais destoantes. Nela, a atmosfera de tranqüilidade deve ser mantida a qualquer custo, mesmo que, para isso, seja necessário dançar

moderna sobre a figura que contrariam a idéia de desvio ou substituição presente nos estudos tradicionais de retórica.

${ }^{3}$ Os termos foram por mim destacados para facilitar a verificação da ironia. 
sem música. Ao fato do envenenamento, as personagens contrapõem o amor e a excitação, que levam os noivos ao quarto. Até a chuva verde de gafanhotos é observada em "extremo sossego", como sinal de esperança. Portanto, há uma grande incoerência entre os acontecimentos e a reação que eles causam, deixando a sensação de inconformidade no leitor. A distância hiperbólica entre causas e conseqüências sugere, ironicamente, a negação da responsabilidade, o afastamento da culpa, a opção pelo esquecimento da ação na guerrilha.

Tal posição assumida pelo colonizador em território africano pode ser também deflagrada pelas imagens que o conto cria como a do Stella Maris e da chuva de gafanhotos. O hotel é o espaço privilegiado dos soldados portugueses que lutam em Moçambique pelos objetivos da política salazarista. As imagens criadas para o local guardam sentidos latentes que estendem esse significado, denunciando também a maneira como as personagens portuguesas lidam com o espaço do Império. O nome Stella Maris reivindica a superioridade portuguesa na expansão colonial: do latim, stella, ae - estrela; mare, maris - mar: estrela do mar. Tal denominação de Estrela do Mar, além de confirmar a posição do hotel, localizado à beira-mar, lembra a brilhante expansão colonial construída a partir da exploração marítima: Portugal, historicamente, definiu-se como a "estrela do mar", também como "guia" de suas colônias.

Por outro lado, essa forma latina evoca, pela similaridade sonora, outra expressão usual em latim, Stella Martis - planeta Marte. Na origem, Mars, martis - Marte, deus da guerra. Marte, personificação da Desgraça, acompanhado pelo Pavor (Deimos), pelo Medo (Fobos) e pela Discórdia (Eris), encarna a força brutal das batalhas. Assim, a expressão Stella Maris, por semelhança fônica, ecoa a qualidade da guerra que ali se faz: uma guerra sangrenta, devastadora, cruel. A comparação subentendida, no entanto, não pode ser delimitada com precisão, ainda que se construam elos semânticos entre os contextos:

HOTEL

Localização à beira-mar

Lugar de concentração dos agentes portugueses da guerrilha
STELLA MARIS

Estrela do mar

Marte

\section{IMPÉRIO}

Superioridade na exploração marítima

Guerrilha sangrenta e devastadora

A ligação metafórica se adensa quando é analisado o espaço que centraliza as ações, aspecto que deixa implícita a escolha de um ponto de vista. N' "Os gafanhotos", o terraço do hotel configura uma determinada impressão: este é um lugar descoberto, amplo, elevado, por onde penetra, com liberdade, a luz do sol. Por encontrar-se em cima, liga-se ao céu e representa, metaforicamente, um lugar de superioridade, de infinitude. O campo semântico de 
elevação, plenitude, grandeza é alimentado, no relato de abertura, pelo uso repetido de vocábulos como "terraço" (21 vezes), "de cima" (10 vezes), "subir" (7 vezes), "Sol" (4 vezes); "astros" (3 vezes), "céu” (2 vezes). A repetição intensiva constrói eco semântico e possibilita a atenção para o papel sugestivo das expressões. Simbolicamente, o céu é o espaço do poder, da sacralidade, da transcendência divina que se liga à soberania: céu/soberano é semelhante a império/rei (CHEVALIER; GHEERBRANT, 1998).

A escolha do terraço, portanto, realça o caráter de magnificência e grandeza de que se quer revestir o Império, alimentado pelos discursos dos oficiais que ali festejam. "Suicidaramse colectivamente como as baleias, ao saberem que nunca seriam autônomos e independentes. Nunca, nunca, até o fim da Terra" (p.20), comenta um major sobre a morte dos negros. Essa fala apresenta o estado de dependência colonial moçambicano como perene. Ao Império Colonial, por sua vez, é atribuído um poder supremo e inabalável. A imagem do cortejo a dançar no terraço deixa implícitas, por fim, idéias de superioridade:

\begin{tabular}{|c|c|c|}
\hline $\begin{array}{l}\text { TERRAÇO DO } \\
\text { STELLA MARIS }\end{array}$ & & $\begin{array}{c}\text { CORTEJO } \\
\text { DO IMPÉRIO }\end{array}$ \\
\hline Lugar amplo, elevado & : : & $\begin{array}{l}\text { Superioridade } \\
\text { portuguesa }\end{array}$ \\
\hline $\begin{array}{l}\text { Proximidade dos astros, } \\
\text { do Sol e do Céu }\end{array}$ & & $\begin{array}{l}\text { Soberania eterna e } \\
\text { Inabalável }\end{array}$ \\
\hline
\end{tabular}

Ligada ao espaço de cima está a figura do invasor, e ao espaço de baixo, a do invadido. De cima vêm os gafanhotos, que podem metaforizar, em todo o romance e inclusive no conto, os soldados portugueses. A relação metafórica está garantida, em princípio, pela cor dos animais. Assim como os gafanhotos, os soldados portugueses são verdes "uma fila interminável de soldados verdes, que partiam em direção ao Norte"; "um suspiro verde como as asas dos gafanhotos girava agora pelo terraço" (p. 33). Já o título do relato de abertura estabelece tal relação, pois torna protagonistas os animais verdes, quando suas personagens principais são os portugueses. Tais insetos, em bando, migram, vindos de fora, invadem e destroem as plantações por onde passam. Tornam presente a imagem bíblica da praga, da multiplicação devastadora, sustentada nos livros do Exxodo $(10,14)$ ao Apocalipse $(9,3)$ e, simbolicamente, lembram o suplício, a calamidade, os tormentos das "invasões históricas" ou “de origem demoníaca” (CHEVALIER; GHEERBRANT, 1998). Assim, o caráter destrutivo dos gafanhotos pode também se estender às ações dos soldados invasores, do português que vem do exterior para impor a desordem e o suplício da guerra: 


\section{BANDO DE GAFANHOTOS}

Pragas vorazes que migram e destroem plantas

$$
\begin{gathered}
\text { Verde } \\
\text { : : }
\end{gathered}
$$

\section{PORTUGUESES}

Invasores históricos que assolam o espaço alheio, impondo a calamidade

Além disso, o espaço de cima guarda a visão branca estereotipada ${ }^{4}$ do negro. Os soldados portugueses reduzem o outro através de vocábulos como "raças servis", "selvagens" que "não inventaram a roda, nem a escrita, nem o cálculo, nem a narrativa histórica" (p.13). Os agentes do Império, pelo seu "claro" e distante olhar, simplificam a identidade do africano, negando o jogo da diferença. Ao estereotipar o black (como o denomina o conto), o europeu impõe toda a sua hegemonia, superioridade, nobreza, "civilização", revelando, assim, o seu próprio narcisismo (BHABA, 1991, p. 198).

Portanto, a figuração do espaço aponta, metaforicamente, para a posição assumida pelos portugueses na guerra das colônias e, assim, favorece o questionamento da sua identidade. "Os gafanhotos" sugere, em situação extrema, a imagem irrealista que os colonizadores mantêm de si mesmos: visualizar uma chuva de gafanhotos - com o significado profundo, ainda que difuso, que este fato pode guardar - em "extremo sossego" - constrói os portugueses como cegos para a ação negativa e destrutiva que exercem em Moçambique.

Por fim, essa primeira parte da narrativa de Lídia Jorge sugere uma das formas do ser português pensar sua ação em África:

$\begin{array}{cll}\text { Céu } & : & \text { visão }+ \text { fantasiosa } \\ \text { Alto } & : & \text { visão }+ \text { fabulosa } \\ \text { Distante } & : & \text { visão }+ \text { redutiva }\end{array}$

\section{Conclusão}

Lançando mão do efeito que a forma peculiar ao conto propicia e intensificando-o pelo uso da ironia e da metáfora, A costa dos murmúrios cria uma imagem polêmica, capaz de inquietar o leitor, que vê os portugueses, em meio às atrocidades da guerra, numa atmosfera festiva, a brindar a união imperial. A forma curta e compacta, o ritmo veloz do conto permite sustentar um "estado de excitação intensa” (POE, 1842) que é ainda mais alimentado pelo distanciamento irônico e pela construção de imagens de semelhança.

\footnotetext{
${ }^{4}$ Conforme conceito de SAID, Edward. Cultura e imperialismo. SP: Cia., 1995, p. 40. Segundo o autor, a noção estereotipada do outro é revestida por expressões como "raças servis", "povos subordinados", "dependência", etc
} 
Desse modo, a literatura, longe de tentar oferecer a integridade do referente, recria-o, deforma-o e, assim, prolonga sua carga semântica. A costa dos murmúrios afasta-se de uma linguagem unívoca que, simplesmente, daria notícia da ação dos colonizadores em África. Ao contrário, pluraliza as versões e, pela imagem, potencializa um "complexo intelectual e emocional" sobre os acontecimentos, que revela o imperceptível e tem um efeito, no mínimo, inquietante. A chuva verde de gafanhotos, a figuração do Stella Maris e seu terraço, ou ainda a ironia do narrador deflagram, sobre a imagem dos portugueses, significados a princípio ausentes. Facilitam a dupla visão, a percepção sensorial que eleva a fantasia e resgata a intensidade do sentimento humano sobre o fato.

Retomando informações externas à obra, foram quinhentos anos de exploração marítima, em que os homens de Portugal se viram como "heróis do mar, nobre povo, nação valente", cuja lembrança constitui "o núcleo da imagem de Portugal que interiormente nos definiu”, conforme afirma Eduardo Lourenço (2000, p. 36). Entretanto, o fim do Império, conseqüência de treze anos de guerra colonial, foi recebido em um estado de inconsciência coletiva:

Treze anos de guerra colonial, derrocada abrupta desse Império, pareciam acontecimentos destinados não só a criar na nossa consciência um traumatismo profundo - análogo ao da perda da independência - mas a um repensamento em profundidade da totalidade da nossa imagem perante nós mesmos e no espelho do mundo. Contudo, nós assistimos a este espetáculo surpreendente: nem uma, nem outra coisa tiveram lugar (idem, p. 55).

Por outro lado, o silêncio sobre a cegueira colonialista em África pode ser um sinal do trauma que o conflito gerou na nação, como pensa Walter Benjamin acerca das vítimas da Primeira Guerra Mundial que, segundo ele, voltaram de lá "mudas". Sobre o comportamento pós-guerra em Portugal esclarece Lídia Jorge em A costa dos murmúrios,

disse às pessoas: "vocês estão caladas, mas as pessoas querem estar caladas sobre isso". Esse é um fenômeno de todas as guerras. Quando chega o momento de exorcizar alguma coisa, não se quer, porque magoa. E, realmente em nossa guerra aconteceram coisas horríveis, detestáveis, péssimas. E esse momento histórico, com um significado mais amplo do que a guerra, era uma imensa mentira política e criou um fundo mentiroso e falso no país. E quando se toca nisso, as pessoas reagem pois não se querem ver no espelho (JORGE, 1993).

Nesse sentido, A costa dos murmúrios deixa vir à tona o trauma da guerra para, pela imagem literária, possibilitar um exame de consciência nacional e reajustar o ser "real" português à sua visão "ideal" de si. O conto de abertura contribui para tal objetivo por permitir ao leitor perceber como a guerra, ao servir de pano de fundo, é assumida como normal e sentir em intensidade como se revela o ponto de vista do opressor, pois é dele a perspectiva que predomina n' “Os gafanhotos". No entanto, as sinalizações irônicas do narrador e a construção 
metafórica estão ali para minar o "discurso oficial", sugerir a sua falência, o quanto é inverossímil e assim indigno de crédito.

\section{Referências}

BHABHA, Homi. A questão do outro. Diferença, discriminação e discurso do colonialismo. In: HOLLANDA, Heloísa Buarque de (org.). Pós-modernismo e política. Rio de Janeiro: Rocco, 1991.

CHEVALIER, Jean; GHEERBRANT, Alain. Dicionário de símbolos. Rio de Janeiro: J. Olympio, 1998.

COSTA LIMA, Luiz. Vida e mimesis. Rio de Janeiro: Ed. 34, 1995.

EIKHENBAUM, B. Sobre a teoria da prosa. In: JAKOBSON, Roman et al. Teoria da literatura. Formalistas russos. Porto Alegre: Globo, 1976.

GENETTE, Gerard. Discurso da narrativa. Lisboa: Vega, 1976.

GOTLIB, Nádia Battella. Teoria do conto. São Paulo: Ática, 1990.

JORGE, Lídia. Entrevistas. GOMES, Álvaro Cardoso. A voz itinerante. São Paulo: EDUSP, 1993.

KERBRAT-ORECCHIONI, Catherine. L'ironie comme trope. Poétique: Revue de Théorie et d'analyse littéraires. Paris, n. 41, fev. p. 108-127, 1980.

LOURENÇO, Eduardo. O labirinto da saudade. Lisboa: Gradiva, 2000.

MOISÉS, Massaud. Dicionário de termos literários. São Paulo: Cultrix, 1995.

PACHECO, Carlos. Criterios para una conceptualización del cuento. In: PACHECO, Carlos; LINARES, Luís Barrera (comp.). Del cuento y sus alrededores. Aproximaciones a una teoria del cuento. Caracas: Monte Avila, 1993. p. 13-27.

POE, Edgar Allan. Review of twice told tales, 1842. In: MAY, Charles E. (ed.) Short story theories. 2 ed. Ohio Univ. Press, 1976. p.45-52.

SAID, Edward. Cultura e imperialismo. São Paulo: Companhia das Letras, 1995.

SARAIVA, Arnaldo. Os duplos do real e os duplos romanescos. (A costa dos murmúrios de Lídia Jorge). Estudos portugueses e africanos, n.19. Campinas, Unicamp, 1992.

VIANU, Tudor. Los problemas de la metáfora. Buenos Aires: Editorial Universitária, 1967.

WELLEK, René; WARREN, Austin. Teoria da Literatura. Lisboa: Europa-América, [s.d]. 